\title{
CRESCIMENTO DE PLÂNTULAS DE MARACUJAZEIRO-AMARELO SOB DIFERENTES LÂMINAS DE IRRIGAÇÃO E USO DE HIDROGEL
}

\author{
Dayane Ávila Fernandes ${ }^{1}$, Maicon Marinho Vieira Araujo ${ }^{1}$, Elisangela Clarete Camili ${ }^{1}$
}

${ }^{1}$ Universidade Federal de Mato Grosso, E-mail: dayavila1@hotmail.com, maiconmarinho@outlook.com, eccamili@hotmail.com

\section{RESUMO}

O objetivo neste trabalho foi avaliar os efeitos do uso de hidrogel associado a diferentes lâminas de irrigação sobre a germinação e desenvolvimento inicial de plântulas de maracujáamarelo. A adição do hidrogel não influenciou nas variáveis avaliadas. A formação de plântulas de maracujá-amarelo apresenta melhores resultados utilizando-se $45 \%$ de água no substrato independente da adição do hidrogel como condicionante.

Palavras-chave: Passiflora edulis, polímero hidroretentor, irrigação, umidade

\section{SEEDLING GROWTH OF YELLOW PASSION FRUIT UNDER DIFFERENT IRRIGATION LEVELS AND HYDROGEL USE}

\section{ABSTRACT}

The objective of this study was to evaluate the effects of hydrogel use associated with different irrigation levels on the germination and initial development of yellow passion fruit seedlings. The addition of the hydrogel did not influence the evaluated variables. The formation of yellow passion fruit seedlings present better results using $45 \%$ water in the substrate regardless the addition of hydrogel.

Keywords: Passiflora edulis, hidroretentor polymer, irrigation, moisture

INTRODUÇÃO

O maracujá é uma cultura de clima tropical que possui ampla distribuição geográfica e grande variabilidade genética. Pertence à família Passifloraceae, formada por 18 gêneros e 630 espécies, sendo o gênero Passiflora o mais importante economicamente, composto por 24 subgêneros e 465 espécies (FERREIRA, 2005). Dentre essa grande variedade de espécies, cerca de 129 são originárias do Brasil e 83 são consideradas endêmicas (CERVI et al., 2010).

Trata-se de uma cultura que abrange diversas áreas do mercado consumidor, dentre elas estão os setores alimentício, farmacêutico, estético, além do uso na 
ornamentação de ambientes. A produção brasileira é de 664.286 toneladas anuais, com boas perspectivas para a ampliação da área cultivada, cerca de 47.032 ha por ano (IBGE, 2009).

Quanto à germinação de sementes do maracujazeiro é conhecido que o início e o término desse processo em Passifloráceas ocorre de forma irregular e desuniforme, podendo, este período, ser de dez dias a três meses, dificultando a formação das mudas (LUNA, 1984).

A água pode ser um fator limitante para a germinação de sementes do maracujazeiro-amarelo, o que pode afetar a porcentagem, a velocidade e a uniformidade deste processo (MARCOS FILHO, 2005). Porém, são necessárias informações mais consistentes sobre a influência da umidade na germinação de sementes de maracujá. Segundo Wagner Junior et al. (2006), a préembebição de sementes de maracujazeiroamarelo não influenciou na velocidade de germinação das sementes, enquanto que Suassuna et al. (2010) determinaram que lâminas de água podem melhorar o desenvolvimento e a eficiência fotoquímica de mudas de maracujá. O uso do hidrogel surge como uma alternativa para minimizar problemas vinculados à deficiência hídrica. De acordo com Azevedo et al. (2002) trata- se de um polímero hidroretentor à base de poliacrilamida, com grande capacidade de retenção e armazenamento de água. Ao ser incorporado ao solo pode aumentar a disponibilidade de água e nutrientes para as plantas, atuando como condicionadores de solo (CAMARA et al., 2011; BERNARDI et al., 2012). Reduzem ainda as perdas por percolação e lixiviação de nutrientes e melhoram a aeração e drenagem do solo, acelerando o desenvolvimento do sistema radicular e da parte aérea das plantas (AZEVEDO et al., 2002). Pesquisas com uso de hidrogéis na fase de germinação de sementes ainda são incipientes, neste aspecto, conta-se com algumas informações com o uso do produto já no campo ou para cultivo por estaquia (HAFLE et al., 2008) com a finalidade de manter a umidade no substrato, reduzindo assim a necessidade de irrigações frequentes.

A partir dessas informações, o objetivo neste trabalho foi avaliar os efeitos do uso de hidrogel associado a diferentes lâminas de irrigação sobre a germinação e desenvolvimento inicial de plântulas de maracujá-amarelo.

\section{MATERIAL E MÉTODOS}

$\mathrm{O}$ experimento foi instalado e conduzido no Laboratório de Sementes da 
Universidade Federal de Mato Grosso, localizado no município de Cuiabá/MT no mês de Outubro de 2012. Utilizaram-se sementes de maracujá da cultivar FB 200, com poder germinativo de $80 \%$, valor obtido através da realização de testes prévios de acordo com as Regras para Análise de Sementes (BRASIL, 2009).

O delineamento experimental foi inteiramente casualizado, em esquema fatorial $2 \times 3$ com quatro repetições de 20 sementes cada. Os tratamentos foram compostos pelo uso ou não de gel hidroretentor misturado ao substrato irrigado com 45, 60 e $75 \%$ da capacidade de retenção.

A determinação da capacidade de retenção foi feita de acordo com as Regras para Análise de Sementes (BRASIL, 2009), onde a quantidade de água a ser adicionada ao substrato foi obtida pesando-se $500 \mathrm{~g}$ do material seco, que foi colocado em filtro de papel, tipo coador de café comercial, em seguida, adicionou-se uma quantidade de água previamente determinada. Após todo o excesso de água ser drenado, o volume foi determinado para o cálculo, por diferença, da quantidade de água que ficou retida no substrato (100\%). Desta quantidade, calcularam-se as quantidades de água a serem adicionadas ao substrato de modo a atingir as porcentagens de 45, 60 e $75 \%$ da capacidade de retenção.

Para o experimento foram utilizadas bandejas de plástico transparente com dimensões de 30 x 21 x $10 \mathrm{~cm}$, com capacidade para 5 litros. $\mathrm{O}$ substrato empregado para o plantio foi o Plantmax $\mathrm{HT}^{\circledR}$, composto pela mistura de casca de pinus, vermiculita e turfa. $\mathrm{O}$ polímero utilizado para o experimento, composto por copolímero de poliacrilato de potássio, foi da marca Forth $\mathrm{Gel}^{\circledR}$, e a quantidade adicionada foi de 4,5 $\mathrm{g} \mathrm{L}^{-1}$ do produto, de acordo com Hafle et al. (2008). O espaçamento de semeadura nas bandejas foi de $3 \mathrm{~cm}$ entre sementes.

Após a semeadura, as caixas foram mantidas em prateleiras de metal com temperatura média de $25^{\circ} \mathrm{C}$ e fotoperíodo de 12 horas. A intensidade luminosa (40 $\mu \mathrm{mol}$ $\mathrm{m}^{-2} \mathrm{~s}^{-1}$ ) foi proporcionada por lâmpadas fluorescentes, fixadas a uma distância de 31 $\mathrm{cm}$ acima da prateleira. Diariamente as caixas correspondentes a cada tratamento eram pesadas para a manutenção das porcentagens que compuseram as lâminas de irrigação.

Aos 28 dias após a semeadura (DAS), determinou-se o comprimento da parte aérea $(\mathrm{cm})$, tomando-se como referência a distância do colo ao ápice do 


\section{CRESCIMENTO DE PLÂNTULAS DE MARACUJAZEIRO-AMARELO SOB DIFERENTES LÂMINAS DE IRRIGAÇÃO E USO DE HIDROGEL}

caule da planta e o comprimento do sistema radicular $(\mathrm{cm})$, considerando-se a distância do colo até a extremidade da maior raiz. Após as medições biométricas, obteve-se a massa de matéria fresca total por meio da pesagem das plântulas inteiras em balança analítica.

Posteriormente, as plântulas foram colocadas em sacos de papel e levadas para secagem em estufa a $80^{\circ} \mathrm{C}$ por 24 horas para determinação da massa de matéria seca. Os dados coletados foram submetidos à análise de variância.

Para comparação das médias entre os tratamentos foi utilizado o teste de Tukey a $5 \%$ de probabilidade. A análise foi realizada utilizando-se o programa ASSISTAT 7.6 (SILVA, 2011).

\section{RESULTADOS E DISCUSSÃO}

As plântulas iniciaram a emergência aos 9 dias após a semeadura (DAS), corroborando com os dados da literatura que afirmam que o início e o término da germinação de passifloráceas ocorrem entre dez dias a três meses (ALEXANDRE et al., 2004). De acordo com os resumos das análises de variância, não houve interação significativa $(p>0,05)$ entre os fatores em estudo (hidrogel x lâminas de irrigação) para qualquer variável avaliada. Quanto ao efeito dos fatores isolados, não houve diferença significativa $(p>0,05)$ sobre o comprimento da parte aérea. Porém, o comprimento da maior raiz e as massas de matérias fresca e seca foram alteradas significativamente pelo conteúdo de umidade no substrato (Tabela 1).

Tabela 1. Resumos das análises de variância para o comprimento de parte aérea e da maior raiz $(\mathrm{cm})$, das massas de matéria fresca e seca de plântulas de maracujazeiro-amarelo (Passiflora edulis Sims f. flavicarpa Deg.) (Cuiabá/MT, 2012).

\section{Teste F}

F.V. G.L. Comprimento Comprimento Massa fresca Massa seca

\begin{tabular}{|c|c|c|c|c|c|}
\hline & & parte aérea & maior raiz & & \\
\hline Hidrogel & 1 & $0,0906^{\mathrm{ns}}$ & $0,4195^{\mathrm{ns}}$ & $0,2836^{\mathrm{ns}}$ & $0,7241^{\mathrm{ns}}$ \\
\hline $\begin{array}{c}\text { Lâminas de } \\
\text { irrigação }\end{array}$ & 2 & $0,6450^{\mathrm{ns}}$ & $4,5892 *$ & $10,3995 * *$ & $5,8320 *$ \\
\hline $\mathrm{H} \times \mathrm{L}$ & 2 & $0,0240^{\mathrm{ns}}$ & $1,3331^{\mathrm{ns}}$ & $0,7403^{\mathrm{ns}}$ & $1,4336^{\mathrm{ns}}$ \\
\hline Resíduo & 18 & & & & \\
\hline $\mathrm{CV}(\%)$ & & 9,08 & 12,92 & 12,53 & 13,30 \\
\hline
\end{tabular}

** significativo $(\mathrm{p}<0,01),{ }^{*}$ significativo $(\mathrm{p}<0,05),{ }^{\mathrm{ns}}$ não significativo, $(\mathrm{H})$ hidrogel, $(\mathrm{L})$ lâminas de irrigação. 
O fato das plântulas do maracujazeiro não apresentarem diferença de desenvolvimento na presença ou ausência do hidrogel provavelmente pode estar ligado ao tipo de substrato comercial utilizado.

Deste modo, vale ressaltar que a vermiculita é uma mica (silicato hidratado de magnésio, alumínio e ferro) que se expande acentuadamente quando aquecida e dentre outras propriedades, é solúvel e capaz de absorver grandes quantidades de água (FASSBENDER, 1978). O tipo de substrato utilizado na produção de mudas é de fundamental importância na determinação da frequência de irrigação e do volume de água a ser aplicado (WENDLING; GATTO, 2002).

Marques e Bastos (2010) trabalhando com diferentes doses de hidrogel no desenvolvimento de mudas de pimentão verificaram que o polímero não promoveu diferenças no sistema radicular e nem no comprimento da parte aérea. Porém, interferiu na massa seca da parte aérea por promover maior número de folhas, com aumento linear de acordo com as doses testadas. Ressaltaram ainda que com o incremento na dose do condicionador, a parte aérea responde com desenvolvimento de folhas e não no crescimento em altura.
Lima et al. (2003) observaram resultados semelhantes ao verificarem ausência da interação entre lâminas de irrigação e doses de hidrogel na produção de mudas de cafeeiro. Somente as lâminas de irrigação promoveram aumento linear da massa seca das folhas e da parte aérea. Ainda conforme esses autores provavelmente o excesso de água aplicada reduziu a importância do uso de um produto absorvente, e influenciou inclusive no acúmulo de massa seca pelas mudas.

O maracujazeiro-amarelo demonstrou ser menos exigente em água nos períodos iniciais de crescimento com a emergência das plântulas. De acordo com os resultados obtidos verificou-se que apenas o comprimento da maior raiz apresentou média inferior na lâmina de 60\% em comparação à lâmina de $45 \%$, que por sua vez apresentou melhores resultados para as três variáveis analisadas (comprimento da maior raiz, massa fresca e seca de plântulas) (Tabela 2).

$\mathrm{O}$ aumento da quantidade de água no substrato para $75 \%$ provocou diminuição do crescimento radicular e na produção das massas de matéria fresca e seca. 
Tabela 2. Comprimento da maior raiz $(\mathrm{cm})$, massas de matéria fresca e seca (g) de plântulas de maracujazeiro-amarelo (Passiflora edulis Sims f. flavicarpa Deg.) sob diferentes lâminas de irrigação (Cuiabá/MT, 2012).

\begin{tabular}{cccc}
\hline Lâminas de & Comprimento & Massa & Massa \\
irrigação $(\%)$ & maior raiz & fresca & seca \\
\hline 45 & $6,11 * a$ & $0,15 \mathrm{a}$ & $0,0163 \mathrm{a}$ \\
60 & $5,70 \mathrm{ab}$ & $0,17 \mathrm{a}$ & $0,0167 \mathrm{a}$ \\
75 & $5,02 \mathrm{~b}$ & $0,13 \mathrm{~b}$ & $0,0135 \mathrm{~b}$
\end{tabular}

*Médias seguidas pela mesma letra na coluna não diferem estatisticamente entre si pelo teste de Tukey ao nível de $5 \%$ de probabilidade.

De acordo com Carneiro (1995) o excesso de umidade no substrato pode criar condições desfavoráveis para a circulação de ar, pois, implica na diminuição da disponibilidade de oxigênio e a energia despendida para o crescimento é obtida pelas raízes por meio da respiração. Assim sendo, se a aeração for prejudicada pelo excesso de umidade, o desenvolvimento radicular também será prejudicado.

Ademais, o excesso de água pode provocar problemas devido a restrições à aeração e aos possíveis danos durante a embebição (MARCOS FILHO, 2005).

\section{CONCLUSÕES}

A formação de plântulas de maracujá-amarelo apresentou melhores resultados utilizando-se $45 \%$ de água no substrato independente da adição do hidrogel como condicionante.

\section{AGRADECIMENTOS}

Ao Laboratório de Sementes da Universidade Federal de Mato Grosso e à técnica de laboratório Sidnéa Aparecida Fiori Caldeira, pela contribuição com conhecimento, bem como o fornecimento de material para realização deste trabalho.

\section{REFERÊNCIAS BIBLIOGRÁFICAS}

ALEXANDRE, R.S.; WAGNER JÚNIOR, A.; NEGREIROS, J.R.S; PARIZZOTTO, A.; BRUCKNER, C.H. 2004. Germinação de sementes de genótipos de maracujazeiro. Pesquisa Agropecuária 
Brasileira, Brasília, v.39, n.12, p.12391245.

AZEVEDO, T.L.F.; BERTONHA, A.; GONÇALVES, A.C.A. 2002. Uso de hidrogel na agricultura. Revista do Programa de Ciências AgroAmbientais, Alta Floresta, v.1, n.1, p.2331.

BERNARDI, M.R.; SPEROTTO JUNIOR, M.; DANIEL, O.; VITORINO, A.C.T. 2012. Crescimento de mudas de Corymbia citriodora em função do uso de hidrogel e adubação. Cerne, Lavras, v.18, n.1, p.67-74.

BRASIL. Ministério da Agricultura, Pecuária e Abastecimento. Regras para Análise de Sementes. Secretaria de Defesa Agropecuária. Brasília: MAPA/ACS5, 2009. 395p.

CAMARA, G.R.; REIS, E.F.; ARAÚJO, G.L.; CAZOTTI, M.M.; DONATELLI JÚNIOR, E.J. 2011. Avaliação do desenvolvimento do cafeeiro conilon robusta tropical mediante uso de polímeros hidroretentores e diferentes turnos de rega. Enciclopédia Biosfera, Goiânia, v.7, n.13, p.135-141.

CARNEIRO, J.G.A. 1995. Variações na metodologia de produção de mudas florestais afetam os parâmetros morfológicos que indicam sua qualidade de mudas florestais. Curitiba. UFPR/FUNEP, Campos dos Goytacazes: UENF, 451p.

CERVI, A.C.; MILWARD-DE-AZEVEDO, M.A.; BERNACCI, L.C. 2010. Passifloraceae. In: JARDIM BOTÂNICO DO RIO DE JANEIRO. Catálogo de plantas e fungos do Brasil. Rio de Janeiro: Andréia Jakobsson Estúdio: Instituto Jardim Botânico do Rio de Janeiro, v. 2, p. 1432-1436.

FASSBENDER, H.W. 1978. Química de suelos: com énfasis en suelos de América Latina. San José: Instituto Interamericano de Ciências Agrícolas, $398 \mathrm{p}$.
FERREIRA, F.R.R. 2005. Recursos genéticos de Passiflora. In: FALEIRO, F. G.; JUNQUEIRA, N. T. V.; BRAGA, M. F. Maracujá: germoplasma e melhoramento genético. Planaltina-DF: Embrapa Cerrados, p. 41-51.

HAFLE, O.M.; CRUZ, M.C.M.; RAMOS, J.D.; RAMOS, P.S.; SANTOS, V.A. 2008. Produção de mudas de maracujazeiro-doce através da estaquia utilizando polímero hidrorretentor. Revista Brasileira de Ciências Agrárias, Recife, v. 3, p. 232-236.

LIMA, L.M.L.; TEODORO, R.E.G.; FERNANDES, D.L.; CARVALHO, H.P.; MENDONÇA, F.C.; CARVALHO, J.O.M. 2003. Produção de mudas de café sob diferentes lâminas de irrigação e doses de um polímero hidroabsorvente. Bioscience in Journal, Uberlândia, v.19, n.3, p.27-30.

LUNA, J.V.U. 1984. Instruções para a cultura do maracujá. Salvador: Epaba, 25p. (Circular Técnica, 7).

MARCOS FILHO, J. 2005. Fisiologia de Sementes de Plantas Cultivadas. 1. ed. Piracicaba-SP: Fundação de Estudos Agrários, v.1, 425p.

MARQUES, P.A.A.; BASTOS, R.O. 2010. Uso de diferentes doses de hidrogel para produção de mudas de pimentão. Pesquisa Aplicada \& Agrotecnologia, Guarapuava, v.3, n.2, p.53-57.

SIDRA/IBGE - Sistema IBGE de Recuperação Automática/Instituto Brasileiro de Geografia e Estatística. 2007. Produção Agrícola Municipal de 2007: Maracujá. Brasília-DF: Ministério do Planejamento, Orçamento e Gestão.

SILVA, F.A.S. 2011. ASSISTAT versão 7.6 beta. Campina Grande-PB: Assistência Estatística, Departamento de Engenharia Agrícola do CTRN Universidade Federal de Campina Grande, Campus de Campina. 
SOUZA, J.G.; BELTRÃO, N.E.M.; SANTOS, J.W. 2001. Fisiologia e produtividade do algodoeiro em solo encharcado na fase de plântula. Pesquisa Agropecuária Brasileira, Brasília, v. 36, n. 3, p. 425-430.

SUASSUNA, J.F.; MELO, A.S.; SOUSA, M.S. S.; COSTA, F.S.; FERNANDES, P.D.; PEREIRA, V.M. 2010. Desenvolvimento e eficiência fotoquímica em mudas de híbrido de maracujazeiro sob lâminas de água. Bioscience Journal, Uberlândia, v. 26, n. 4 , p. 566-571.

WAGNER JÚNIOR, A.; ALEXANDRE, R.S.; NEGREIROS, J.R.S.; PARIZZOTTO, A.; BRUCKNER, C.H. 2006. Influência da escarificação e do tempo de embebição das sementes sobre a germinação de maracujazeiro (Passiflora edulis f. flavicarpa Degener). Revista Ceres, Viçosa, v. 52, n. 301, p. 369-378.

WENDLING, I.; GATTO, A. 2002. Substratos, adubação e irrigação na produção de mudas. Viçosa: Aprenda Fácil Editora, 166 p. 